\title{
Gilberto Freyre e nossa "Modernidade Tropical": entre a originalidade e o desvio
}

SEREIO B. F. TAUOLARO"

\section{Resumo}

As questões que orientam o presente artigo são duas: em que medida Freyre coloca-se a tarefa de desconstruir um quadro de referência conceitual percebido como responsável pela perpetuação da imagem de incomensurabilidade entre a experiência societal brasileira e aquela das "sociedades modernas civilizadas"? Qual lugar o ambiente físico tropical ocupa nesse projeto? Examino três hipóteses de trabalho: 1) Há em Freyre uma consciente tentativa de relativizar o protagonismo (epistemológico, normativo e estético-expressivo) exclusivo reivindicado por sociedades tradicionalmente tidas como modelares da modernidade; 2) $\mathrm{O}$ trópico foi, desde o princípio de sua obra, uma peça-chave nesse ambicioso projeto intelectual, graças a predicados tomados por singulares, catalisadores de uma experiência social tida por inovadora e irreprodutível pelas sociedades europeias hegemônicas; 3) A ambiciosa intenção freyreana de desestabilizar a centralidade epistemológica da "modernidade europeia" vê-se inadvertidamente frustrada na medida em que essa mesma experiência (e o tipo de sociabilidade imaginado como exclusivamente seu) é retomada como padrão de medida para se aferir a singularidade da modernidade no Brasil.

Palavras-chave: Modernidade no Brasil; Gilberto Freyre; Sociologia brasileira

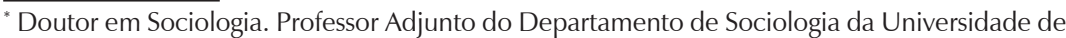
Brasília (Brasil).E-mail: sergiotavolaro@hotmail.com
} 


\section{Gilberto Freyre and the Brazilian "Tropical Modernity": between originality and deviation ${ }^{1}$}

\section{Abstract}

Two questions underlie the argument in this article: to what extent Freyre takes up the task of deconstructing a conceptual framework that is perceived as perpetuating the image of incommensurability between the Brazilian societal experience and that of the "modern civilized societies"? What place does the tropical environment occupy in this project? I examine three operational hypotheses: 1) Freyre makes a conscious attempt to relativize the exclusive (epistemological, normative and aesthetic-expressive) role claimed by societies traditionally regarded as models of modernity; 2 ) since the beginning of his work, the tropics was a key part of such ambitious intellectual project, because of peculiarities that would work as catalysts for an innovative social experience non-reproducible in hegemonic European societies; 3) the ambitious Freyrean attempt to destabilize the epistemological centrality of "European modernity" results inadvertently frustrated, insofar as this very experience (and the kind of sociability deemed to be peculiar to it) is resumed as a pattern to assess the singularity of Brazilian modernity.

Keywords: Modernity in Brazil, Gilberto Freyre. Brazilian sociology

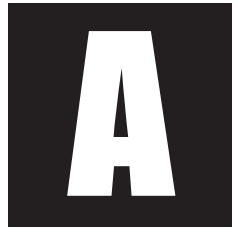

primeira sociedade moderna constituída nos trópicos com característicos nacionais e qualidades de permanência é uma das maneiras tipicamente expressivas com que Gilberto Freyre qualifica a experiência brasileira² Com frequência apontada como uma das principais alavancas da "démarche cultural" observada no pensamento brasileiro do sé-

\footnotetext{
${ }^{1}$ Uma primeira versão deste artigo foi apresentada no Congresso da ALAS Recife 2011. Agradeço o apoio do Decanato de Pesquisa e Pós-Graduação da Universidade de Brasília.

${ }^{2}$ Ver Freyre (2000a, p. 86). Referências análogas podem ser encontradas em Freyre (2000b, p. 169), Freyre, (2004, p. 47) e Freyre (2010, p. 205).
} 
culo XX (Pallares-Burke, 2005; Bastos, 2006) 3), sua vasta e prolífica obra é, ao mesmo tempo, repleta de referências ao protagonismo do trópico em nossa formação social. Igualmente intrigante talvez seja o fato do autor de Casa-grande \& senzala (1933), declarado entusiasta de nossa hibridez cultural, vislumbrar o trópico não como obstáculo, mas, ao contrário, como elemento-chave do que considera ser a singular experiência da modernidade no Brasil. O que dizer dessa tentativa de compatibilizar ênfases analítico-explicativas tão diversas? Em verdade, Elide Rugai Bastos já teve oportunidade de salientar essa fascinante combinação de aspectos e fatores na interpretação de Gilberto Freyre. De acordo com a autora, a articulação entre patriarcalismo, interpenetração de etnias/cultura e trópico constitui-se na unidade explicativa do pensamento freyreano (Bastos, 2006, p. 11). Também atento a essa curiosa articulação, Ricardo B. de Araújo (1994) chama atenção para a presença capital do "meio físico" em sua obra, complementada por um tratamento da raça sob forte inspiração "neolamarckiana"4.

Em diálogo crítico com o empreendimento interpretativo de Freyre, Jessé Souza (2000) enxerga a existência de uma importante mudança de ênfase nos trabalhos de maturidade em relação àqueles do ainda jovem autor de Sobrados e mucambos (1936). Para Souza, a preocupação com o "elemento mesológico" ganha magnitude inédita apenas nas reflexões e propostas do já maduro e consagrado Freyre. Assim, de acordo com Jessé Souza, [s]e nos escritos da juventude os outros elementos estão subordina-

\footnotetext{
${ }^{3}$ A esse respeito, Elide R. Bastos defende que 'Casa-grande \& senzala' marca definitivamente a necessidade de assumirem-se os valores culturais em torno dos quais gira o social, os quais levam a sociedade brasileira a se distinguir das outras. É nesse ponto de inflexão que se coloca a obra freyreana (Bastos, 2006, p. 71).

${ }^{4}$ De acordo com Araújo (1994, p. 39), tal definição neolamarckiana de raça, baseando-se na ilimitada aptidão dos seres humanos para se adaptar às mais diferentes condições ambientais, enfatiza acima de tudo a sua capacidade de incorporar, transmitir e herdar as características adquiridas na sua - variada, discreta e localizada - interação com o meio físico (...).
} 
dos à dimensão cultural (...), nas obras de maturidade a dimensão mesológica assume o lugar de proeminência (...) (Souza, 2000, p. 211)5. Vale dizer, o autor atribui a tal mudança de ênfase motivações de ordem política ou, para ser mais preciso, geopolítica, isto é, uma preocupação quanto à necessidade de se resistir às investidas imperialistas de potências não tropicais.

Acredito ser possível uma leitura distinta dessa questão. Em primeiro lugar, seguindo nas entrelinhas as sugestões de Bastos (2006) e Araújo (1994), parece-me que o papel protagonista conferido ao trópico é um aspecto fundamental desde os trabalhos do ainda jovem Freyre ${ }^{6}$, inclusive naquele que posteriormente o elevaria à condição de clássico do pensamento social brasileiro. Se assim for, isso implica reconhecer que, mesmo a contrapelo de argumentos-chave de Casa-grande \& senzala, "aspectos mesológicos" muitas vezes são assumidos como variáveis independentes da experiência social brasileira, lado a lado com (e não subordinados a) fatores sociais e culturais. Atrelado a esse problema de reflexão, há outro igualmente interessante. Talvez Jessé Souza esteja correto quanto às motivações de natureza geopolítica que, segundo ele, teriam conduzido o Freyre maduro à proposição de uma "tropicologia". Mas se for possível ver nessa "motivação geopolítica" também o desejo de desafiar a centralidade epistemológica da "modernidade europeia" - isto é, de desestabilizar sua posição modelar em relação a toda e qualquer experiência societal moderna -, então, acredito eu, tal mote pode ser igualmente encontrado desde suas célebres obras de juventude.

\footnotetext{
${ }^{5}$ Com essa "concepção neolamarckiana de ciência", abrir-se-ia a possibilidade de consideração simultânea de elementos tão heterogêneos como as influências biológicas, mesológicas e culturais na determinação da especificidade de uma formação social singular (Souza, 2000, p. 211).

${ }^{6}$ Já em seu Manifesto regionalista (1926), pode-se ler que [r]egionalmente pode ser estudada, sem sacrifício do sentido de sua unidade, a cultura brasileira, do mesmo modo que a natureza; o homem da mesma forma que a paisagem (Freyre, 1976, p. 37).
} 
É em torno desses problemas cruzados que se situam os interesses de reflexão do presente artigo: até que ponto o empreendimento explicativo-interpretativo da formação social brasileira realizado por Freyre envolve um exercício de desconstrução de certo quadro de referência conceitual que, em sua percepção, falhava ao perpetuar a imagem de subalternidade, por assim dizer, de nossa experiência societal em relação às ditas "sociedades modernas civilizadas"? Ademais, em que medida o autor pernambucano busca o suporte de outros fatores, para além de variáveis socioculturais, em sua tentativa de compreender as peculiaridades de nossa "modernidade tropical"? Minha primeira hipótese de trabalho é que, nesse esforço de apreensão da "singularidade brasileira", Freyre reivindica a necessidade de se relativizar o protagonismo (epistemológico, normativo e estético-expressivo) exclusivo de sociedades tradicionalmente tidas como modelares da modernidade. Daí a maneira sistemática por meio da qual intenta consubstanciar a ideia do Brasil como a "primeira sociedade moderna nos trópicos". Nesse exato sentido, conforme buscarei mostrar mais adiante, talvez seja possível afirmar que Freyre antecipa algumas críticas recentes ao discurso sociológico da modernidade. De acordo com minha segunda hipótese de trabalho, o trópico foi desde o início, e assim permaneceu posteriormente, uma peça-chave nesse ambicioso projeto intelectual, graças a predicados tomados por singulares, catalisadores de uma experiência social tida por inovadora e irreprodutível pelas sociedades europeias hegemônicas. De suas peculiaridades físicas adviriam qualidades que ajudariam a explicar a originalidade da experiência brasileira em relação à "modernidade europeia e anglo-saxônica". Por fim, conforme minha terceira hipótese, a ambiciosa intenção freyreana de desestabilizar a centralidade epistemológica da modernidade europeia vê-se inadvertidamente frustrada na medida em que essa mesma experiência (e o tipo de sociabilidade imaginado como exclusivamente 
seu) é retomada como padrão de medida para se aferir a singularidade da modernidade no Brasil. Com isso, a meu ver, a originalidade que nosso autor pretende conferir à sociedade brasileira acaba por reafirmar um estigma que ele próprio almejava desmontar: o de desvio do "centro".

II

Há uma delicada e esclarecedora intersecção entre algumas das preocupações de Gilberto Freyre e de Manoel Bomfim. Freyre talvez seja o exemplo mais sonoro de uma geração de intérpretes que buscou levar a termo um novo tipo de tratamento da questão racial no Brasil, cujos contornos já podiam ser identificados em A América Latina: males de origem (1905). Manoel Bomfim, bem sabemos, dirigiu uma severa crítica à "teoria científica do valor das raças" (Bomfim, 1993, p. 245). Ora, ao eleger variáveis sociais como os registros por meio dos quais essa problemática deveria ser prioritariamente enquadrada, Freyre e outros destacados nomes da "geração de 1930" consumaram, enfim, algo que Bomfim já havia asseverado: a necessidade de se desconstruir as teorias racistas - desvelando as relações de poder que as sustentavam - como condição sine qua non à compreensão das peculiaridades históricas e sociais do Brasil. Interessa-me em especial o fato dessa reflexão de Bomfim entrelaçar-se a outra problematização também bastante ousada: sua obra sugere que a compreensão de nossas alardeadas singularidades requeria colocar em suspenso uma série de imagens, categorias e estereótipos acerca das sociedades latino-americanas projetados "desde fora" (Bomfim, 1993, p. 38), que logravam encontrar fortes ressonâncias domésticas (Bomfim, 1993, p. 43). Se quisessem conhecer-se a fundo, tais sociedades deveriam perscrutar-se de maneira autônoma, atentas aos juízos que desde pronto as condenavam a uma posição de inferioridade em relação aos 
povos ditos mais civilizados. Nesse sentido, e sem qualquer pretensão de atribuir-lhe termos apenas hoje correntes, parece-me que Bomfim ambicionava desvelar certa "geopolítica do conhecimento" (Mignolo, 2005) que invariavelmente confirmava a superioridade das sociedades anglosaxônicas e, em contrapartida, a inferioridade/subalternidade das experiências latino-americana e brasileira”. A meu ver, sua crítica à "teoria científica da raça" consistia em peça-chave nesse exercício de avaliação e revisão epistemológica, que envolvia certo exercício de "provincianização" ${ }^{\prime 8}$ de categorias de entendimento empregadas pela "Europa" e projetadas sobre a "América do Sul".

Esse brevíssimo cotejo entre Freyre e Bomfim joga luz sobre a problemática que move o presente artigo. Inspirado por discussões recentes no seio do pensamento social engajadas em um esforço de problematização de alguns dos pilares do discurso sociológico clássico da modernidade $^{9}$, pergunto-me, em que medida, também, Gilberto Freyre vislum-

\footnotetext{
${ }^{7}$ Com vistas à realização de uma escavação da fundação imperial/colonial da 'ideia' de América Latina que o capacite a desvelar certa "geopolítica do conhecimento", Walter Mignolo (2005, p. X-XI) fala-nos da existência de um "diferencial epistêmico de poder", ancorado em diferentes localidades geo-históricas, graças ao qual distintos paradigmas e perspectivas de conhecimento são hierarquicamente dispostos. Justamente nesse sentido, Mignolo defende a necessidade de se adotar uma perspectiva da colonialidade, em contraposição à predominante perspectiva da modernidade (a europeia) como condição sine qua non para se desnudar os processos e bases epistemológicas por meio dos quais "pessoas e continentes fora da Europa" eram vislumbrados ou como "objetos" ou, no máximo, como "sujeitos cujas perspectivas não contavam" (Mignolo, 2005, p. XII). Para uma crítica a essa concepção, ver Domingues (2009). ${ }^{8}$ Num programa de reflexão que guarda semelhanças com aquele de Walter Mignolo (2005), Chakrabarty (2000) empreende um esforço de "provincianização" da Europa que envolve a suspensão de uma série de conceitos, noções e pressupostos que fazem da experiência europeia um padrão de medida para outras experiências societais, nas suas diferentes dimensões (política, cultural, social, normativa, econômica, etc). De acordo com o autor, [a] Europa aparece diferente quando vista a partir do interior de experiências de colonização ou de inferiorização em partes específicas do mundo (Chakrabarty, 2000, p. 16).

${ }^{9}$ Refiro-me, aqui, tanto às reflexões em torno da noção de "modernidades múltiplas" como aquelas sob a ampla (e, por certo, imprecisa) rubrica de "condição pós-colonial". Ver, por
} 
brava a experiência societal brasileira como uma espécie de "lugar de enunciação alternativo", cuja atenta consideração seria capaz de abrir espaço à crítica da centralidade epistemológica, gozada por referências cognitivas, normativas e estéticas (ditas anglo-saxônicas, tanto em suas origens como em suas vivências), comumente tidas por exclusivas à "civilização europeia"? Ou seja: almejava Freyre lançar mão de um referencial epistemológico atento à "geopolítica do conhecimento" (Mignolo, 2005), alerta ao movimento de conceitos que, de maneiras mais ou menos sutis, tenderiam a perpetuar a imagem de subalternidade atrelada à experiência brasileira? Nessa mesma direção, seria possível identificar em sua obra um esforço deliberado de "provincianização" da "perspectiva da modernidade" (Chakrabarty, 2000; Mignolo, 2005), acompanhado da adoção de um referencial cognitivo imune às atribuições de "falta", "ausência" ou "incompletude" (Chakrabarty, 2000) frequentemente imputadas às assim chamadas "experiências periféricas"? ${ }^{10}$

III

A "virada cultural" levada a cabo por Freyre em sua interpretação da formação social brasileira revelou-se um golpe de misericórdia na imagem de incompatibilidade biológica do negro e do indígena à "civilização".

exemplo, Eisenstadt (2000; 2010), Chakrabarty (2000), Mignolo (2005), Quijano (2005), Said (1979), Domingues (2002), Wittrock (2000), Tibi (2006), Casanova (2006). Uma apreciação crítica desse debate, com ênfase na "contribuição pós-colonial", pode ser encontrada em Costa (2006). Segundo o autor, a característica comum dos estudos pós-coloniais é justamente o esforço de esboçar, pelo método da desconstrução dos essencialismos, uma referência epistemológica crítica às concepções dominantes de modernidade (Costa, 2006, p. 117).

${ }^{10}$ Chakrabarty (2000, p. 28) fala-nos do problema de ignorância assimétrica, em meio ao qual a Europa funciona como um referente silencioso no conhecimento histórico. 
Para Freyre (2000a, p. 371), como havia sido para Bomfim (1993, p. 238), as causas de comportamentos "imorais" comumente atribuídos ao negro (tanto quanto ao indígena) deveriam ser buscadas não em pretensas essências biológicas, mas, prioritariamente, em causas sociais (históricas, econômicas, culturais). Bem sabemos que à recusa do status de sujeitos plenos aos segmentos não brancos da população brasileira, compartilhada por parte substantiva e influente de nossa intelectualidade durante o século XIX e início do XX, nas mais diversas matrizes (Schwarcz, 1993), Freyre respondeu com um argumento radical: a cultura negra africana teria sido a principal alavanca civilizadora da sociedade brasileira, graças à sua superioridade em relação não só à [cultura] dos indígenas como à da grande maioria dos colonos brancos (Freyre, 2000a, p. 357).

Talvez esse ousado reenquadramento da problemática étnico-racial pudesse ser tomado como evidência de sua opção definitiva pela exclusividade de variáveis sociais nos esforços de compreensão e explicação da formação brasileira. Fato é que, em uma conferência na qual sugere o ineditismo e originalidade de sua própria obra ${ }^{11}$, Freyre declarou que, ainda no início da década de 1940, eram muito recentes os estudos que vão estabelecendo o primado do fator cultural - inclusive o econômico - entre as influências sociais e de solo, de clima, de raça, de hereditariedade de família, que concorreram para a formação da sociedade brasileira (Freyre, 1940). Sabe-se que, anos antes, o autor de Casa-grande \& senzala já havia afirmado ter aprendido com Franz Boas "a considerar fundamental a

\footnotetext{
${ }^{11}$ Refiro-me à conferência intitulada "Atualidade de Euclydes da Cunha", pronunciada em 29/10/1940 na Biblioteca do Ministério das Relações Exteriores a convite da Casa do Estudante do Brasil. Para uma interessante avaliação da interpretação de Euclides da Cunha por Gilberto Freyre, ver Nicolazzi (2010).
} 
diferença entre raça e cultura", distinção sobre a qual se assentava todo o plano de sua ambiciosa obra interpretativa ${ }^{12}$. Também em Sobrados e mucambos, Freyre mostrou-se enfático:

A disparidade entre subgrupos, numa sociedade como a brasileira, vem antes do conflito entre as fases ou os momentos de cultura que, encarnados a princípio pelas três raças diversas, hoje o são por populações ou 'raças' puramente sociais e também por diferenças regionais de progresso técnico. (Freyre, 1996, p. 658).

De fato, naquele novo ambiente intelectual - no qual, além dele mesmo, despontariam figuras como Sergio Buarque de Holanda e Caio Prado Jr. - fatores propriamente sociais eram alçados de maneira veemente à condição de variáveis explicativas da aclamada "singularidade brasileira"13. Os comentários de Freyre (1940) a Euclides da Cunha e a sua célebre obra Os Sertões serviam, dentre outras coisas, para enfatizar tais novidades e, na mesma proporção, deslegitimar fatalismos racialistas ou determinismos biológicos embutidos em esforços prévios de compreensão de nossa formação social (Nicolazzi, 2010): condições econômicas e sociais, favoráveis ou desfavoráveis ao desenvolvimento humano (Freyre, 2000a, p. 45) deveriam ser o foco prioritário das atenções científicas.

O lugar e a importância de Gilberto Freyre nessa nova maneira de enxergar o Brasil já foram mais do que merecidamente reconhecidos (Cardoso, 1993; Davidoff, 1982; Larreta e Giucci, 2007; Velho, 2008; Thomaz,

\footnotetext{
${ }^{12}$ Maria Lúcia Pallares-Burke (2005) teve ocasião de mostrar que essa filiação às ideias de Boas não foi tão imediata e coincidente com o período em que Freyre cursou o mestrado na Universidade Columbia, em Nova York, como a princípio ele mesmo queria fazer crer em várias de suas declarações.

${ }^{13}$ Obras como Evolução Política do Brasil (1933) e Raízes do Brasil (1936) são, obviamente, emblemáticas daquele novo contexto.
} 
2001; Villas-Bôas, 2006). Ainda assim, quero examinar um aspecto de sua interpretação que me parece ter permanecido obscurecido frente a outras questões na agenda de pesquisa e reflexão em torno de sua obra. Trata-se do lugar que o meio físico, ou o ambiente natural, ocupa em suas tentativas de desvelar a aclamada "singular experiência social brasileira" (Tavolaro, 2008; Tavolaro, 2011). Não é difícil entender o porquê desse obscurecimento: ante a intenção (insistentemente enfatizada pelo próprio autor) de alçar a cultura e as condições sociais e econômicas para o primeiro plano da análise social, talvez se esperasse que aspectos físicos (geológicos, climáticos, genéticos, dentre outros) fossem marginalizados ou, no limite, completamente deslegitimados como fontes explicativas relevantes da peculiaridade brasileira. $\mathrm{Ou}$ seja, tendo sido Freyre um dos propulsores dessa "revolução cultural" em nosso pensamento social, era de se esperar que "fatores naturais/ambientais" desaparecessem por completo ou ocupassem apenas e tão somente um lugar residual em suas reflexões. Afinal, como compatibilizar "cultura" e "natureza" em um quadro epistemológico no qual a prioridade explicativa é supostamente deslocada em favor de fatores sociais?

Ocorre que, a meu ver, ao menos nesse aspecto em particular, a ruptura não é tão radical quanto por vezes sugerida ou mesmo anunciada. Num dos ensaios que compõem o livro O luso e o trópico (1961), Freyre lançou uma questão expressiva dessa ambiguidade:

Será que essa atitude, ao mesmo tempo de regalo estético e de curiosidade de saber, de conhecer, de esclarecer, característica de tantos escritores portugueses dos séculos das Descobertas e das aventuras ultramarinas e, ainda hoje, de portugueses e brasileiros em face da natureza, da mulher e de condições ecologicamente tropicais de vida, deva ou possa ser considerada efeito ou resultado exclusivo das provocações dessa natureza e dessas condições, isto é, da sua atuação sobre o espírito ou a sensibilidade do luso ou do seu descendente ou continuador brasileiro? (Freyre, 2010, p. 134-35). 
A tomar por sua própria apreciação à abordagem de Euclides da Cunha há pouco aludida, a resposta de Freyre a tal questão não deixa de causar certa surpresa: "Exclusiva, não direi. Mas decisiva, ouso sugerir que sim" (Freyre, 2010, p. 134).

Teria Freyre logrado encontrar um lugar seguro para a natureza em meio à sua "revolução cultural"? Afinal de contas, qual papel ele reservava ao meio físico nos retratos projetados em torno da "singularidade brasileira"? Ana Carolina Santos (2008) fala-nos de uma tensão entre duas ideias de natureza presentes em Freyre: 'meio' e 'paisagem' convivem em seu pensamento, convivência que sugere uma contradição entre a proclamada ruptura com os determinismos biológicos da geração anterior (Santos, 2008, p. 87). Em relação ao estatuto da noção de meio ambiente em Casa-grande \& senzala, Ricardo Benzaquen de Araújo, por sua vez, defende que

[e]m vez de ser percebida como um terceiro elemento isolado, que poderia unicamente se somar aos anteriores, esta noção deve ser compreendida como uma espécie de intermediária entre os conceitos de raça e de cultura, relativizando-os, modificando o seu sentido mais freqüente e tornando-os relativamente compatíveis entre si. (Araújo, 1994, p. 39).

De maneira análoga, Enrique Larreta e Guillermo Giucci também argumentam que em Gilberto Freyre a noção de meio é chave (Larreta e Giucci, 2007, p. 455). Segundo os autores, em seu esforço para "desessencializar" o tratamento então preponderante a respeito da questão racial no Brasil, a importância atribuída ao meio - quanto à sua capacidade de modificar e modelar caracteres psíquicos e comportamentais - não se restringe à sua dimensão social. Ela se expandiria de modo a também considerar aspectos físicos e bioquímicos (Larreta e Giucci, 2007) ${ }^{14}$ Seja

\footnotetext{
${ }^{14}$ Segundo Larreta e Giucci, [e]m Casa-grande \& senzala discute-se com interesse a hipótese neolamarckiana da transmissão dos caracteres adquiridos, que é, em parte, uma expressão radical da importância atribuída ao meio (Larreta e Giucci, 2007, p. 456).
} 
como for, em primeiro lugar, há fortes indícios de que, ao invés de presença residual, o meio físico é um aspecto bastante recorrente na interpretação freyreana. Em vez de mero cenário ou pano de fundo sobre o qual se manifestariam e se desdobrariam exclusivamente aspectos e fenômenos culturais, sociais e econômicos, o ambiente físico é tratado como um elemento ativo, capaz de conformar e moldar a experiência sociocultural brasileira (Tavolaro, 2011). Nesse sentido, compreender a "peculiar modernidade brasileira" requereria levar em consideração a particularidade de nossa natureza bem como seus impactos sobre os homens, suas relações, seus valores e expressões estéticas.

Para começar, é mister lembrar que a interpretação de Gilberto Freyre ergueu-se apoiada no pressuposto de uma singularidade brasileira. A partir dessa base, tratou de combater a imagem de incompatibilidade entre civilização e trópico (Freyre, 2010, p. 236). Conforme observei anteriormente, Freyre aprazia-se em defender que fomos a primeira civilização moderna nos trópicos, aquela que, beneficiando-se a um só tempo de referências "europeias e extraeuropeias", logrou fixar-se e estabelecerse em "condições ecologicamente tropicais de vida" - leia-se, em um ambiente físico diverso e até mesmo hostil aos padrões de vida europeus. Foram muitas as fontes e influências intelectuais desse autor, cujo ecletismo não cansa de ser salientado (Pallares-Burke, 2005). Freyre, bem sabemos, não mediu esforços para explicar, interpretar e celebrar essa experiência tida como verdadeiramente inédita. Fronteiras disciplinares - num momento em que, a bem da verdade, elas não existiam da maneira como hoje as concebemos - jamais se lhe revelaram um real constrangimento. Dados, métodos, problemáticas, perspectivas, interesses, questões e informações a um só tempo etnográficos, sociológicos, historiográficos, jornalísticos, estéticos, médicos e literários, aliados a relatos de viagem, serviram-Ihe, todos eles, de ferramentas para consumar seu ambicioso 
projeto intelectual (Lehmann, 2008). É comum chamar-se atenção para seu esforço de desmontagem de certo "complexo de inferioridade", graças ao qual se perpetuava a imagem de um Brasil claudicante rumo à civilização. Por esse novo olhar, não seríamos mera manifestação distante e imperfeita da civilização anglo-saxônica; ao invés disso, a "primeira civilização moderna nos trópicos" seria uma realização distintamente acabada além de, em inúmeros aspectos, um modelo a ser admirado - e, guardadas as suas irredutíveis e irreprodutíveis especificidades, tomado como referência por outras sociedades.

Compartilho da opinião segundo a qual o problema da "singularidade brasileira" encontra em Freyre uma modulação diversa daquela disseminada entre os principais intérpretes do final do século XIX: não mais como objeto de lamento, e sim como uma experiência inédita e, ao mesmo tempo, verdadeiramente positiva ${ }^{15}$. Mas mesmo nesse ponto, há alguns aspectos inusitados que merecem exame mais cuidadoso. A meu ver, em meio a esse esforço de desmontagem do estigma de inferioridade da sociedade brasileira - no qual, conforme salientei, o próprio meio físico tropical é mobilizado como arma decisiva -, a imagem que Freyre projeta dessa suposta "singularidade" escora-se em referências epistêmicas que, inadvertidamente, reforçam o diagnóstico da "incompletude" da experiência da modernidade no Brasil em relação aos chamados "centros hegemônicos" (leia-se, a certas "sociedades anglo-saxônicas"). Dessa feita, o ambiente físico tropical, identificado como um dos aspectos responsáveis por nossa singularidade, converte-se inesperadamente em um dos fatores igualmente responsáveis pela reafirmação da imagem de "desvio" dessa experiência (Tavolaro, 2011).

\footnotetext{
${ }^{15}$ Segundo Larreta e Giucci, para Freyre, [a] modernidade híbrida e tropical brasileira não é apenas possível, mas desejável; tem tantos (ou mais) méritos que outros modelos históricos, do ponto de vista ético, estético e civilizador (Larreta e Giucci, 2007, p. 422).
} 
Em Novo mundo nos trópicos (1959), Freyre argumentou que a civilização que o Brasil está desenvolvendo nos trópicos não é puramente ocidental ou européia. É, sob vários aspectos, extra-européia. Ou mais-queeuropéia (Freyre, 2000b, p. 161). Ora, ao afirmarem que Freyre não rompe totalmente com a narrativa do progresso, Larreta e Giucci ressaltam que [s]ua própria dependência do vocabulário das ciências sociais modernas o torna propenso a pensar as diversas culturas em termos de adiantadas e atrasadas (Larreta e Giucci, 2007, p. 465). A meu ver, essa dependência vocabular de que falam Larreta e Giucci assenta-se nas seguintes bases: Freyre não logra livrar-se de uma dada imagem do padrão de sociabilidade moderno alimentada por certo discurso sociológico da modernidade (Tavolaro, 2005). O autor reforça essa imagem na medida em que, implicitamente, ampara-se em referenciais caros àquele discurso, quais sejam, diferenciação social, secularização, separação público/privado e disjunção sociedade/natureza. Em seus retratos da sociedade brasileira, percebem-se descompassos em cada um desses aspectos: ao fim e ao cabo, não teríamos experimentado o mesmo grau de diferenciação social, de secularização, de separação entre âmbitos públicos e privados e, por fim, de disjunção entre sociedade e natureza - portanto, o inverso do pretensamente observado nas "sociedades modernas anglo-saxônicas" (Tavolaro, 2008; Tavolaro, 2011). Sua apreciação do meio físico tropical, vislumbrado como fator absolutamente ativo nessa singular sociedade, contribui de maneira determinante para o reforço da imagem de "desvio".

Explico-me: de acordo com o discurso sociológico hegemônico da modernidade, processos de modernização conduzem inexoravelmente ao divórcio entre a dinâmica da sociedade e a do mundo natural, isto é, ao aprofundamento da distância entre os domínios da cultura e da natureza. Quanto mais moderna a sociedade - reza tal discurso - mais externos Ihes são a dinâmica e os imperativos do mundo natural (Giddens, 1991). 
Mutatis mutandis, a inigualável capacidade de controle racional-impessoal e de manipulação técnica da natureza, observada entre as sociedades modernas, decorreria precisamente de sua posição de completa exterioridade em relação ao mundo natural (Parsons, 1971). Ora, conforme argumentarei a seguir, bastante distinta é a maneira como Freyre vislumbra a relação sociedade brasileira/natureza tropical. Ao invés de distância e exterioridade, prevalece a imagem de porosidade e influência mútua. Ademais, em vez de uma relação pautada pela racionalidade, suas análises sugerem que a sociedade brasileira e o ambiente tropical imbricam-se em meio a um universo simbólico marcadamente encantado e dotado de referências valorativas substantivas. Para desenvolver esse conjunto de argumentos, debruçar-me-ei sobre trabalhos que expressam momentos diversos da produção freyreana.

\section{IV}

Na conhecida passagem do prefácio à $1 \underline{a}$ edição de Casa-grande \& senzala, em que ratifica a distinção entre raça e cultura, Freyre argumentou ter aprendido a discriminar entre os efeitos de relações puramente genéticas e os de influências sociais, de herança cultural e de meio (Freyre, 2000a, p. 45). O termo meio é, pois, enunciado de maneira independente, desvinculado de fatores socioculturais. Larreta e Giucci observam que, ao lado do sistema da família patriarcal, do escravismo e das misturas racial e cultural, um dos temas centrais de Casa-grande \& senzala é precisamente o dos trópicos, vislumbrados a um só tempo como obstáculo e meio ambiente propício à modernidade híbrida e tropical brasileira (Larreta e Giucci, 2007, p. 422). A conotação que Freyre pretende conferir ao termo meio ganha contornos mais claros em parágrafos posteriores, quando evoca Spengler e Boas para frisar a importância das influências 
ambientais sobre as características físicas e psicológicas dos indivíduos. Ainda naquele prefácio, com o propósito de já sugerir o quadro de referência através do qual codificaria o encontro do português com o novo ambiente, Freyre advertia que a despeito de não se dever esquecer a ação dos recursos técnicos dos colonizadores no sentido de impor ao meio formas e acessórios estranhos de cultura, dever-se-ia também admitir-se a tendência do meio físico e principalmente do bioquímico (biochemical content) no sentido de recriar à sua imagem os indivíduos que the cheguem de várias procedências (Freyre, 2000a, p. 48).

Conforme observei acima, a se considerar as opiniões comumente aceitas acerca das novidades interpretativas trazidas por Freyre, essa advertência proferida pelo próprio autor talvez causasse estranheza. Uma possibilidade de leitura seria talvez considerá-la mera reminiscência, isto é, resquício de um quadro intelectual anterior ${ }^{16}$, cujas referências não mais ecoariam em Freyre a não ser como elementos muito marginais. Mas não é isso o que ocorre. São profusas as passagens que denotam a incrível relevância atribuída a aspectos do "meio físico". É claro que salientar tal importância conferida ao ambiente natural não nos autoriza a subestimar as diferenças que o próprio Freyre pretendeu demarcar, e que de fato consumou, entre suas reflexões e as de intérpretes que o precederam. Não seria correto, por exemplo, equiparar sua interpretação indistintamente às de Silvio Romero e Euclides da Cunha. Se em Romero e Euclides a natureza faz-se sentir na formação social brasileira com pouquíssimas mediações de

\footnotetext{
${ }^{16}$ Para uma interessante discussão do ambiente intelectual do final do século XIX, delineado pela "orientação naturalista européia" - em que "o biológico foi adotado como modelo epistemológico legítimo de explicação científica da sociedade" -, ver Botelho (2003, p. 78-79 e demais páginas do artigo). Ver, também, Dória (2007).
} 
outra ordem (em certas ocasiões até mesmo ao largo dessas outras mediações) ${ }^{17}$, em Freyre a força dessa variável claramente dilui-se na medida em que interage com fatores socioculturais. É verdade que em Sociologia (1945), talvez sua obra de maior fôlego teórico, nosso autor diz-nos que:

Nenhum problema é mais profundamente ecológico - e ao mesmo tempo sociológico - que o da adaptação do homem ao meio físico, ao conjunto de condições de solo, de vegetação e de vida animal dentro do qual vai estabelecer sua posição, seu status, sua situação de homem social e não apenas de indivíduo biológico: de portador, transplantador, deformador ou renovador de cultura, de instituições, de formas de vida social (Freyre, 1973, p. 453).

Apesar disso, pondera que

a Ecologia chamada social ou humana - ou seja, a Sociologia ecológica ou regional - não pode ser comparada com exatidão à Ecologia vegetal ou à Ecologia animal. O homem, como reconhecem os principais sociólogos ecologistas e os próprios ecologistas de Chicago, é capaz de agir em plano mais alto de comportamento que o animal no seu processo de adaptação (Freyre, 1973, p. 441-442).

É difícil negar, pois, que aos fatores socioculturais (dentre os quais se sobressaem especialmente a mistura cultural, a família patriarcal, a escravidão, além do latifúndio monocultor orientado à exportação) Freyre conferia ênfase muito superior em relação às interpretações do final do século

\footnotetext{
${ }_{17}$ Para Romero, o meio físico é um poderoso agente jurídico, influindo nos costumes, nos hábitos, no trabalho, na economia e em tantos outros elementos determinadores de nossa especial fisiologia e psicologia nacional (Romero, 2001, p. 28). Já Euclides, refletindo sobre as influências do clima tropical nas populações, argumenta que [a] seleção natural, em tal meio, opera-se à custa de compromissos graves com as funções centrais, do cérebro, numa progressão inversa prejudicialíssima entre o desenvolvimento intelectual e o físico, firmando inexoravelmente a vitória das expansões instintivas e visando o ideal de uma adaptação que tem, como conseqüências únicas, a máxima energia orgânica, a mínima fortaleza moral (Cunha, 1981, p. 59).
} 
$X I X^{18}$. Ainda assim, é indisfarçável o lugar de destaque que a natureza ocupa em sua equação. Aliás, em uma expressiva passagem de Casa-grande \& senzala, o autor diz-nos que [d]iante da possibilidade da transmissão de caracteres adquiridos, o meio, pelo seu físico e pela bioquímica, surge-nos com intensa capacidade de afetar a raça, modificando-lhe caracteres mentais que se tem pretendido ligar a somáticos (Freyre, 2000a, p. 353). Seguindo-se, pois, as sugestões de Araújo (1994), parece que essa forte "inclinação neolamarckiana" realmente o incentivou a prestar considerável atenção ao trópico, transformando de certa forma condições físicas e geográficas em culturais (Araújo, 1994, p. 58). De fato, são muitos os indícios de que clima e terra comportam-se, em sua obra, como fatores ativos na formação da sociedade brasileira. Em Casa-grande \& senzala, o autor diz-nos que

[e]mbora o clima ninguém o considere o senhor-deus-todopoderoso de antigamente, é impossível negar-se a influência que exerce na formação e no desenvolvimento das sociedades, senão direta, pelos efeitos imediatos sobre o homem, indireta pela sua relação com a produtividade da terra, com as fontes de nutrição, e com os recursos de exploração econômica acessíveis ao povoador (Freyre, 2000a, p. 88).

O impacto condicionante desses aspectos ganha cores ainda mais vivas quando se propõe explicar a pretensa aptidão (ou "aclimatabilidade", como gostava de dizer) do português à vida continuada nos trópicos:

Nas condições físicas de solo e de temperatura, Portugal é antes África do que Europa. O chamado 'clima português' de Martone, único na Europa, é um clima aproximado do

\footnotetext{
${ }^{18}$ Conforme observei anteriormente, Elide R. Bastos sustenta que a unidade explicativa na interpretação freyreana constitui-se a partir da articulação entre patriarcalismo, interpenetração de etnias/cultura e trópico (Bastos, 2006, p. 11). Contudo, Bastos entende que muito embora esses três marcos definidores da formação nacional apareçam correlacionados, cabe ao patriarcalismo lugar de destaque, como elemento de encontro dos outros dois (Bastos, 2006, p. 81).
} 
africano. Estava assim o português predisposto pela sua mesma mesologia ao contato vitorioso com os trópicos: seu deslocamento para as regiões quentes da América não traria as graves perturbações da adaptação nem as profundas dificuldades de aclimatação experimentadas pelos colonizadores vindos de países de clima frio (Freyre, 2000a, p. 85).

É verdade que, para Freyre, as condições mesológicas tropicais nem sempre mostraram-se favoráveis ao empreendimento colonizador: teria o português deparado-se com um ambiente muitas vezes inóspito a formas de vida permanentes, assentadas sobre bases econômicas e sociais mais elaboradas (Freyre, 2000a, p. 88-89). Mas mesmo esse argumento não faz outra coisa senão reforçar a imagem de uma íntima relação entre o meio físico e a sociedade brasileira em formação.

V

Em vista do que foi exposto, parece-me que, nas reflexões de Gilberto Freyre, a peculiaridade do meio físico tropical manifesta-se e faz sentir seu impacto sobre a "singular experiência brasileira" em ao menos três direções facilmente discerníveis: em uma dimensão objetiva, em uma direção simbólico-comportamental e, por fim, em uma dimensão estético-expressiva.

Em relação à dimensão objetiva, importa observar que Freyre vislumbra a natureza tropical como algo verdadeiramente distinto e peculiar em relação a outros ambientes físicos. E essa especificidade natural teria ajudado a moldar nossa sociedade em seus processos de formação. Em Nordeste, Freyre diz-nos que [a] qualidade do solo, completada pela atmosfera, condicionou como talvez nenhum outro elemento, essa especialização regional da colonização baseada na cana-de-açúcar (Freyre, 2004, p. 48). É em tom de celebração que vemos o autor argumentar que [n]es- 
sas manchas de terra pegajenta foi possível fundar-se a civilização moderna mais cheia de qualidades, de permanência e ao mesmo tempo de plasticidade que já se fundou nos trópicos (Freyre, 2004, p. 47). Pudera: essa civilização teria erguido-se sobre um solo de riqueza profunda, terra doce e acomodatícia, diferente do ranger de areia dos sertões (Freyre, 2004, p. 47). Assim é que, para o sucesso dessa civilização teriam também contribuído "condições particularmente favoráveis de solo, de atmosfera, de situação geográfica" (Freyre, 2004, p. 48).

Ao lado de passagens como essa, nas quais a exuberância tropical é tomada como um dos mais destacados aspectos da singularidade brasileira, abundam também as advertências quanto aos desafios naturais enfrentados pelo colonizador. Longe da imagem de "paraíso terreal", cuja opulência material convidaria hábitos folgazões e avessos ao trabalho árduo, Freyre realça o comportamento muitas vezes hostil daquele ambiente, a exigir notável esforço daqueles que aqui buscavam estabelecer-se em bases seguras. "Tudo era aqui desequilíbrio", diz-nos.

Grandes excessos e grandes deficiências, as da nova terra. $O$ solo, excetuadas as manchas de terra preta ou roxa, de excepcional fertilidade, estava longe de ser o bom de se plantar nele tudo o que se quisesse, do entusiasmo do primeiro cronista. Em grande parte rebelde à disciplina agrícola. Áspero, intratável, impermeável. Os rios, outros inimigos da regularidade do esforço agrícola e da estabilidade da família. Enchentes mortíferas e secas esterelizantes - tal o regime de suas águas. $E$ (...) viveiros de larvas, multidões de insetos e de vermes nocivos ao homem (Freyre, 2000a, p. 89).

Esses traços, segundo o autor, impuseram desafios que a muitos colonizadores revelavam-se praticamente intransponíveis. Se o português logrou sobrepujá-los, isso se deveria, em larga medida, a seu passado ambiental já híbrido, que o dotou de admirável "aclimatabilidade". Outras tantas empresas europeias não tiveram a mesma sorte. 
Ainda na obra de Freyre, o meio tropical manifestar-se-ia e faria impactar-se também em uma dimensão simbólico-comportamental. Em Nordeste, Freyre sustenta que [a] terra macia do litoral e da 'mata' do extremo Nordeste e do Recôncavo da Bahia parece ter influído sobre os seus próprios senhores [...] amaciando homens do Norte agrário inteiro (Freyre, 2004, p. 52). Também nesse caso, Freyre argumenta que, previamente à sua chegada nos trópicos americanos, o português já havia sido moldado por um meio físico diverso do europeu do norte, a saber, o clima africano. Ora, o ar da África, um ar quente, oleoso, amolecia

nas instituições e nas formas de cultura as durezas germânicas, corrompendo a rigidez moral e doutrinária da Igreja medieval, tirando os ossos ao Cristianismo, (...) à disciplina canônica, ao direito visigótico, ao latim, ao próprio caráter do povo (Freyre, 2000a, p. 80).

Tais instituições e referências morais europeias, já "amolecidas" por circunstâncias mesológicas diversas da Europa do norte, encontrariam aqui circunstâncias e condições ainda menos favoráveis para se manifestar e prosperar em sua forma pura. Não é de se estranhar, pois, que em trabalhos posteriores a Casa-grande \& senzala, Freyre referiu-se à existência de comportamento e cultura lusotropicais e de valores tropicais de cultura (Freyre, 2010, p. 108-111). Esses "valores de natureza tropical", cabe ressaltar, eram vislumbrados como "escandalosamente diferentes dos europeus" (Freyre, 2010, p. 143) ${ }^{19}$. Ora, de acordo com o autor, estamos - ao que parece - diante de um processo de formação de um terceiro homem ou de uma terceira cultura - um homem simbioticamente lusotropical, uma cultura simbio-

\footnotetext{
${ }^{19}$ Também em Novo mundo nos trópicos, Freyre sustenta que "valores culturais europeus" vinham adquirindo novos aspectos nas áreas tropicais americanas. Segundo o autor, [a]s condições físicas dessas áreas têm sido as primeiras a exigir a adaptação de vários desses valores e de formas e estilos de cultura de origem européia a novo ambiente (2000b, p. 169).
} 
ticamente lusotropical (...); e que se vem formando por ter o português (...) renunciado, como nenhum europeu até hoje, à sua pureza, quer étnica, quer cultural, a favor de formas híbridas de homem e de cultura, das quais vê, participando raças, ambientes e culturas tropicais transeuropeizados pela presença entre eles do mesmo português (Freyre, 2010, p. 108).

Há ainda outra faceta da alardeada influência do meio tropical sobre os comportamentos, os hábitos e a cultura daquela sociedade em formação, potencializada pela mistura do colonizador com as gentes e culturas indígenas, tidas como mais próximas da natureza. Como sugere Freyre, a vida selvagem toda, através de suas diversas fases, se achava impregnada de um animismo, de um totemismo (Freyre, 2000a, p. 208). Isso se explicaria pelo fato de, segundo o autor, haver entre os ameríndios desta parte do continente, como entre os povos primitivos em geral, certa fraternidade entre o homem e o animal, certo lirismo mesmo nas relações entre os dois (Freyre, 2000a , p. 170). Pouco ou nenhum espaço haveria, naquelas circunstâncias, para um convívio impessoal e desencantado entre os próprios homens e deles com a natureza. Muito pelo contrário, medos, pavores e superstições primitivas, forjados e alimentados à sombra de uma cultura da floresta tropical, indicam estarmos próximos da floresta tropical como, talvez, nenhum povo moderno civilizado (Freyre, 2000a, p. 209) - traço acentuado com mais força por ainda nos acharmos à sombra do mato virgem (Freyre, 2000a, p. 209).

Por fim, na obra de Freyre, a natureza tropical teria impactado sobre a dimensão estético-expressiva da "singular experiência brasileira". Freyre sugere que

as condições de espaço físico parecem influir sempre sobre o desenvolvimento de formas de arte (...), notando-se das artes plásticas que se têm desenvolvido principalmente em espaços de clima temperado ou quente, e da música e da 
literatura, que se têm desenvolvido principalmente em espaços de clima frio (Freyre, 2010, p. 174).

Ora, segundo o autor, na realidade cotidiana de ambientes lusotropicais predominam cores quentes, figuras de mulher e de homem pardas, amarelas, avermelhadas, alaranjadas, morenas, todos eles seres de uma forte pigmentação (Freyre, 2010, p. 88). Naquelas circunstâncias, parecia-lhe mais do que esperado que pintores, arquitetos, urbanistas, escultores, decoradores e jardineiros levassem em consideração as relações do homem com o meio, isto é, com o sol, com a luz, com as cores, com as formas, com as sombras características desse meio ou a ele peculiares (Freyre, 2010, p. 186). Tratar-se-ia, de acordo com Freyre, de [clores e formas de plantas, de animais, de árvores, de montanhas, de morros, de paisagens, de plantas e formas e cores de mulheres e de homens criados pelo trópico ou aqui recriados pela mestiçagem (Freyre, 2010, p. 186). É sintomático, pois, que o autor vislumbrasse esse cenário como sendo marcado por relações mais livres e mais íntimas do homem com a natureza, em circunstâncias francamente favorecidas pelo clima e pela luz tropicais (Freyre, 2010, p. 193) ${ }^{20}$.

$\mathrm{Na}$ verdade, nem mesmo a língua portuguesa teria escapado a essas influências mesológicas. Freyre sustentava que não o clima em si, mas o modo social de vida condicionado por este ou por aquele tipo de clima, pode ter sobre a língua falada por populações situadas em clima muito frio ou muito quente, repercussões nada desprezíveis (Freyre, 2010, p. 237). Dessa feita, não surpreende o peso conferido às condições tropicais

\footnotetext{
${ }^{20}$ Assim, por exemplo, parecia-lhe que [n]os trópicos, o desenvolvimento da arte dos jardins ligados a blocos de residências coletivas favorece a arte dos murais de azulejo no exterior dos edifícios, a arte das esculturas públicas, os concertos e as exportações de quadros ao ar livre, o teatro, os mamulengos, as danças, os jogos artísticos igualmente ao ar livre, a própria missa campal acompanhada de cerimônia e atos religiosos de caráter artístico ao ar livre (Freyre, 2010, p. 192-193).
} 
no processo de descolamento da língua portuguesa em relação a outros idiomas neolatinos, em virtude da crescente tropicalização das suas vozes, dos seus sons, do seu modo de corresponder a estilos e a conveniências de populações de várias origens étnicas e culturais integradas em países quentes (Freyre, 2010, p. 236).

Na contramão, pois, da ruptura inúmeras vezes reivindicada pelo próprio Freyre em relação às gerações de intelectuais que o precederam, vem à tona a imagem de uma sociedade cujas singularidades decorreriam, em certa medida, das peculiaridades de seu ambiente físico tropical. Resta-nos discutir até que ponto esse inusitado destaque conferido à natureza colocou em xeque o ambicioso projeto de considerar "a primeira civilização moderna dos trópicos" em pé de igualdade com as ditas "sociedades modernas centrais".

VI

Em uma recente avaliação do perfil da produção sociológica nacional, Sérgio Costa levanta a tese de que não existe, hoje, uma reflexão na Sociologia brasileira orientada, diretamente, para intervir nos principais debates teóricos desenvolvidos no âmbito da disciplina (Costa, 2010, p. 26). Ao mesmo tempo, porém, percebe, nesse mesmo cenário intelectual, a multiplicação de investigações que têm implicado a revisão de algumas das premissas sobre as quais assentam as teorias aceitas como válidas (Costa, 2010, p. 26). De fato, talvez nessa última direção aludida por Costa, tornaram-se mais frequentes trabalhos preocupados com o vigor crítico dos clássicos do pensamento social brasileiro em seus diferentes momentos. Em sintonia com uma agenda de pesquisa internacional dedicada a esmiuçar os meandros do discurso sociológico da modernidade ${ }^{21}$,

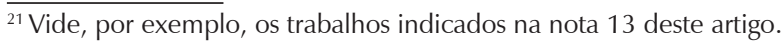


ganham espaço reflexões que almejam examinar em que medida alguns de nossos mais célebres intérpretes lograram, à sua época, livrar-se de armadilhas epistemológicas caras àquele mesmo discurso, responsáveis por obliterar as assimetrias embutidas nos processos de enunciação científica. Comprovado seu sucesso no sentido de empregar e construir noções e conceitos alternativos aos "hegemônicos", talvez fôssemos autorizados a concluir que muitas daquelas interpretações da formação brasileira anteciparam críticas e ponderações ao discurso da modernidade que hoje alcançam escopo internacional.

Nesse exato sentido, Elide Rugai Bastos defende que várias questões atualmente colocadas no âmbito das ciências humanas para o entendimento da sociedade foram, de vários modos, objeto da reflexão de autores brasileiros ao longo dos anos (Bastos, 2011, p. 52). Em análise acerca do legado da obra de Darcy Ribeiro, Adélia Miglivich Ribeiro, por sua vez, sustenta que "há conexões entre a utopia darcyniana e alguns pós-coloniais". Segundo a autora, Darcy [i]nseriu, em caráter definitivo, os povos americanos no mapa-múndi, não como pré-estágios civilizatórios, mas como pólos atualizados de um mesmo sistema econômico moderno (Ribeiro, 2011, p. 27). De maneira análoga, João Marcelo Maia defende que o pensamento brasileiro pode falar não apenas do Brasil, mas também sobre dilemas modernos globais a partir de um ponto de vista distinto daquele formulado no mundo europeu e anglo-saxão (Maia, 2009, p. 156). Para ele, isso abre um espaço comparativo que descentre nossa própria pretensa singularidade (Maia, 2009, p. 166).

Considerada sob um viés crítico a eventuais assimetrias de enunciação embutidas no discurso sociológico da modernidade, parece-me realmente que a obra de Freyre mostrava-se alerta a certa geopolítica do conhecimento (Mignolo, 2005) que tendia a enquadrar sociedades como a brasileira sob o signo do "desvio". Nessa mesma direção, parece-me 
que suas reflexões também ambicionavam indicar lugares, pontos de vista e enunciados alternativos por meio dos quais a experiência societal brasileira pudesse ser vislumbrada em sua positividade (e não à sombra de qualquer "falta" ou pretensa "incompletude"). Ainda assim, quero retornar a uma das questões centrais deste artigo: em que medida essa chave interpretativa realmente logrou, conforme nos sugerem Larreta e Giucci, reivindicar a modernidade da cultura brasileira, examinando-a em pé de igualdade com centros hegemônicos (Larreta e Giucci, 2007, p. 423)? A meu ver, esse aspecto do projeto intelectual freyreano viu-se frustrado em seus objetivos, na medida em que se amparava em referências epistemológicas que inadvertidamente reforçavam a imagem do Brasil como um "desvio" daquelas mesmas sociedades hegemônicas.

Uma vez mais, a sensibilidade de Freyre à geopolítica epistemológica que circunscrevia as ciências sociais de sua época é indisfarçável ${ }^{22}$. As discussões em torno das noções de tropicologia e lusotropicologia, delineadas pelo autor a partir da década de 1950, podem ser vistas como tomadas de posição audaciosas nesse embate epistemológico. O que estava em jogo era a reivindicação de um novo saber científico, para além das referências "norte-europeias", de um tipo de conhecimento mais ajustado às pretensas peculiaridades das "civilizações modernas tropicais". Os ensaios que compõem $O$ luso e o trópico consistem numa reafirmação do valor e das promessas de sociedades que, sob a determinante influência lusa, lograram erguer-se e sedimentar-se nos trópicos. Em sua defesa da tropicologia, o meio tropical reaparece não só como um dos pilares

\footnotetext{
${ }^{22}$ Segundo o próprio autor, [s]abemos que, quase todas as interpretações atuais do que seja a civilização européia - mesmo a russa ou a ibérica - em face das não européias, têm sido elaboradas por antropólogos, sociólogos, historiadores e sobretudo, pensadores, cujas personalidades se desenvolveram dentro de circunstâncias, se não sociais, de cultura ou de disciplina intelectual, peculiares à Europa mais especificamente européia (Freyre, 2010, p. 294).
} 
de sustentação da celebrada singularidade brasileira, mas também como uma importante arma nessa batalha. Tratava-se, por um lado, de defender que novas formas de vida social estabeleceram-se de maneira perene em ambientes tropicais, forjando técnicas, saberes, hábitos e padrões de comportamento próprios, adequados às novas circunstâncias sociais e aos imperativos e possibilidades físico-ambientais. Mas havia uma reivindicação adicional, tão importante quanto a primeira: argumentava-se que, por um lado, o universo cognitivo e as ferramentas conceituais da "civilização norte-europeia" não eram os únicos à disposição das ciências sociais. Por outro, e talvez de maneira ainda mais ousada, chamava-se atenção para a inadequação dessas ferramentas ante a tarefa de captar a singularidade da experiência brasileira.

Daí, em primeiro lugar, a defesa não só da necessidade, mas também da legitimidade de uma ciência especial que procure sistematicamente estudar o experimento lusitano na América tropical, como parte de um esforço lusitano de adaptação de homens e valores europeus a espaços tropicais (Freyre, 2010, p. 41) - ou seja, de um estudo científico sistemático de uma forma, um processo, um estilo simbiótico de transculturação, ao mesmo tempo que de adaptação do europeu aos trópicos (Freyre, 2010, p. 25). Esta ciência especial seria justamente a lusotropicologia. Estava em questão a construção de um saber melhor equipado frente ao desafio de apreender o sistema de relações dos homens e de suas culturas adventícias ou já mistas com determinado espaço físico-cultural - o espaço tropical (Freyre, 2010, p. 72). A necessidade desse novo saber justificarse-ia, também, pelas evidentes limitações das ciências sociais etnocêntricas. Para Freyre, as razões dessas limitações estariam, dentre outras coisas, no fato dessas ciências basearem-se apenas na experiência ocidental de sociedades que se têm suposto a sociedade humana, de culturas que se tem intitulado a civilização (Freyre, 2010, p. 98-99). Nosso autor pronun- 
cia de maneira veemente seu repúdio ao que entendia ser uma postura unilateral dessas ciências sociais, colocando-se em defesa de perspectivas verdadeiramente universais (Freyre, 2010, p. 99).

Mas esse embate epistemológico pretendido por Freyre intentava avançar em uma segunda direção. Conforme observei acima, o autor ressaltava que as experiências societais tropicais (especialmente a luso, mas também a hispanotropical) teriam logrado produzir saberes, formas de vida, hábitos e comportamentos libertos das convenções norte-europeias e condizentes com as condições tropicais de vida (Freyre, 2010, p. 114). Dotados de inestimável valor, esse produtos deveriam receber o devido reconhecimento das sociedades centrais. Diz-nos Freyre que a plasticidade do português, sua disponibilidade para confraternizar com as gentes dos trópicos e de misturar seus valores e os seus sangues com os extraeuropeus de terras ou regiões quentes (Freyre, 2010, p. 156) foi algo que demandou cuidadoso conhecimento da realidade tropical (Freyre, 2010, p. 156). Nesse sentido, [e]stendendo-se por áreas tropicais, o português, desde o começo dessa sua expansão, foi um europeu atento ao conhecimento de ervas, plantas e vegetais que foi descobrindo entre as populações nativas (Freyre, 2010, p. 135). Ora, Camões é louvado justamente por ser um dos primeiros portugueses a lançar as bases para um conhecimento sistemático da natureza, do homem, das coisas tropicais, que correspondesse a necessidades portuguesas de expansão em países ou terras de clima, solo, condições de vida, formas e cores de paisagem, de homem, de mulher, de menino, para as quais o lusitano se sentia, como hoje se sente, particularmente predisposto (Freyre, 2010, p. 150).

A miscigenação cultural e racial, a posição proeminente da família patriarcal e de seus códigos de sociabilidade, a centralidade do latifúndio exportador baseado na mão de obra escrava e, conforme tenho buscado argumentar, a peculiaridade do meio físico tropical, todos esses elemen- 
tos contribuíram de maneira determinante, na visão de Gilberto Freyre, para que a formação social brasileira - e, posteriormente, para que a experiência da modernidade no Brasil - ganhasse traços distintivos em relação às "sociedades centrais". Por certo, em vez de conceber esses traços como obstáculos à formação de uma verdadeira civilização, Freyre os tomava por constitutivos de uma experiência conclusa, dotada de identidade própria. Nesse registro, essa singular experiência - conforme tenho frisado, saudada por Freyre como a primeira civilização moderna nos trópicos - poderia ser tomada em pé de igualdade em relação a outras civilizações modernas.

Ocorre, porém, que essa imagem da singularidade brasileira ergueuse apoiada em referências cognitivas que acabaram por reafirmar o estigma do "desvio" (Tavolaro, 2011). Primeiramente, à luz do retrato projetado por Freyre - e na contramão do discurso sociológico da modernidade - tal experiência seria marcada por um baixo grau de diferenciação social. A centralidade do latifúndio, esse cosmos totalizante sob cujas asas realizavam-se tarefas a um só tempo econômicas, militares, jurídicas, culturais e religiosas, tolheu o desenvolvimento autônomo de outras esferas sociais, paralelas a ele e capazes de diversificar os imperativos e códigos de sociabilidade que lhe eram mais característicos. Por séculos, nem mesmo as funções políticas conseguiram dele se desgarrar, ficando a administração da colônia atada às referências, imperativos e necessidades do latifúndio. Conforme pode-se depreender a partir das reflexões de Sobrados e mucambos acerca de nossa "europeização" (dessa vez sob a influência da Inglaterra e da França) que, na visão de Freyre, aprofundou-se ao longo do século XIX, o produto final da modernização brasileira permaneceu algo diverso das sociedades centrais justamente porque aquele passado colonial (e a configuração de sociabilidade que lhe fora peculiar) logrou deixar seu legado de maneira determinante. 
Em segundo lugar, a tomar pelo retrato projetado por Freyre, a sociedade brasileira não experimentou o processo de racionalização social (ou, para usar a sugestiva expressão de Weber, de "desencantamento do mundo" e, posteriormente, de plena secularização) nas mesmas proporções observadas nas sociedades centrais. Nossa religiosidade - um misto de catolicismo mágico com as coloridas religiões africanas, somado ao animismo das religiões autóctones - revelou-se resiliente e consideravelmente ativa, mesmo após as mais recentes ondas de europeização e modernização por que passamos. Tratava-se, segundo Freyre, de um catolicismo adaptado às nossas condições de vida tropical e de povo de formação híbrida (Freyre, 1996, p. 651-52), que se revelou elemento poderoso de integração brasileira (Freyre, 1996, p. 651). A contrapelo do discurso sociológico da modernidade, esse baixo grau de secularização embutido no retrato da formação brasileira forjado por Freyre sugere-nos, uma vez mais, a ideia de uma experiência moderna desviante das sociedades centrais - tomadas como palco de profunda e extensa racionalização.

Em terceiro lugar, pelas lentes de Freyre, os âmbitos de sociabilidade públicos e privados, tanto quanto suas relações, teriam se configurado entre nós de maneira igualmente diversa daquela observada nas civilizações anglo-saxônicas. Enquanto nessas últimas a existência de fronteiras claras prevenia confusões indesejadas entre os interesses públicos e os privados, algo muito distinto teria ocorrido no Brasil: como um legado da centralidade que o pater familias outrora desfrutara no tecido social brasileiro, ainda hoje certas vontades particulares logram prevalecer sobre qualquer esboço de vontade coletiva que eventualmente ensaie constituir-se. Uma vez mais, ainda que as ondas de modernização intensificadas no século XIX tenham provocado o ocaso do patriarcalismo colonial, tudo indica que a família entre nós não deixará completamente de ser a influência criadora, conservadora e disseminadora de valores que foi na sua fase patriar- 
cal (Freyre, 1996, p. XC) - e com ela, muito provavelmente, o personalismo e seus códigos de sociabilidade característicos. Dessa feita, a plena separação entre o público e o privado, que para o discurso sociológico da modernidade é também um dos pilares da sociabilidade moderna, não encontraria eco na "singular experiência brasileira" retratada por Freyre.

Por fim, conforme busquei demonstrar, a maneira como nosso autor concebe a relação sociedade brasileira/meio físico tropical enseja-nos a imagem de uma relação marcadamente porosa, em certos momentos quase que simbiótica. Tratar-se-ia não só de um ambiente diverso do europeu (mais intenso, mais colorido, mais vibrante, e, de certa forma, até mesmo mais hostil e inóspito a uma vida regrada/sistemática), como também capaz de se traduzir em símbolos, padrões de comportamento, valores diversos (os "valores tropicais") e referências estéticas distintas das europeias. Nada poderia ser mais distante do retrato projetado pelo discurso sociológico da modernidade, para o qual uma das marcas distintivas da sociabilidade moderna é sua autonomia em relação ao mundo natural, aliada a sua capacidade de submetê-lo impiedosamente aos seus imperativos e necessidades ${ }^{23}$.

Note-se, pois, os andaimes sobre os quais se ergue a imagem freyreana da pretensa "singularidade tropical brasileira": um cenário social indiferenciado (Estado/mercado/sociedade imbricam-se e confundem-se), apenas timidamente "desmagicizado"/secularizado (concepções mágicas de mundo informam a vida cotidiana e as instituições sociais), no qual os

\footnotetext{
${ }^{23}$ Nos dizeres de Anthony Giddens, enquanto que [n]a maior parte das culturas pré-modernas, mesmo nas grandes civilizações, os seres humanos se viam em continuidade com a natureza, nas sociedades plenamente modernas (industrializadas), os seres humanos vivem num 'ambiente criado' (...). Não somente o ambiente construído das áreas urbanas mas a maioria das outras paisagens também se torna sujeita à coordenação e controle humanos (Giddens, 1991, p. 66).
} 
âmbitos públicos e privados acham-se entrelaçados (via de regra, à mercê dos interesses privados de pessoas que ocupam posições de maior destaque, poder e prestígio) e, por fim, em que uma natureza bastante peculiar faz valer seu peso sobre os valores, instituições, padrões comportamentais e expressões de cunho estético (Tavolaro, 2008). Tais referências epistemológicas são justamente aquelas por meio das quais o próprio discurso sociológico da modernidade distingue configurações societais as mais diversas da experiência moderna. Àqueles contextos marcados por baixo grau de diferenciação social, incipiente secularização, indiferenciação entre o público e o privado e, por fim, porosidade na relação sociedade/ natureza, esse discurso sociológico reserva as designações pré-modernas, quase-modernas, semi-modernas, dentre outras. Por meio dessas designações, decreta-se a incompletude de sua condição moderna. Ora, ao permanecer atado a essas referências, e a despeito de buscar desmontar o protagonismo epistemológico exclusivo da "modernidade anglo-saxônica", Freyre acaba inadvertidamente reafirmando o estigma da "originalidade brasileira" como uma espécie de "desvio da modernidade central".

\section{Referências}

ARAÚJO, R. B. Guerra e paz: Casa-grande \& senzala e a obra de Gilberto Freyre nos anos 30. Rio de Janeiro: Ed. 34, 1994.

BASTOS, E. R. As criaturas de prometeu: Gilberto Freyre e a formação da sociedade brasileira. São Paulo: Global, 2006.

BASTOS, E. R. Atualidade do pensamento social brasileiro. Sociedade e Estado, Brasília, DF, v. 26, n. 2, p. 51-70, 2011.

BOMFIM, M. A América Latina: males de origem. Rio de Janeiro: Topbooks, 1993.

BOTELHO, A. "Na contracorrente do naturalismo: relações sociais na interpretação do Brasil de Manoel Bomfim". Temáticas, Campinas, v. 11, n. 21/22, p. 75-100, 2003. 
CARDOSO, F. H. Livros que inventaram o Brasil. Novos Estudos: revista do Centro Brasileiro de Análise e Planejamento, São Paulo, n. 37, p. 21-35, 1993.

CASANOVA, J. Religion, European secular identities, and European integration. In BYRNES, T. and KATZENSTEIN, P. (eds). Religion in an Expanding Europe. New York: Cambridge University Press, p. 65-92, 2006.

CHAKRABARTY, D. The idea of provincializing Europe. In: CHAKRABARTY, D. Provincializing Europe: Postcolonial thought and historical difference. Princeton: Princeton University Press, p. 3-23, 2000.

COSTA, S. Desprovincializando a sociologia: a contribuição pós-colonial. Revista Brasileira de Ciências Sociais, São Paulo, v. 21, n. 60, p. 117-134, 2006.

COSTA, S. Teoria por adição. In: MARTINS, C. e MARTINS, H. (orgs). Horizontes das ciências sociais no Brasil: sociologia. São Paulo: ANPOCS, p. 25-51, 2010.

CUNHA, E. Os sertões: campanha de canudos. Rio de Janeiro: Francisco Alves, 1981.

DAVIDOFF, C. A ideologia da modernização em Gilberto Freyre e Oliveira Vianna. Perspectivas, São Paulo, v. , p. 29-38, 1982.

DOMINGUES, J. M. Global modernization, 'coloniality' and a critical sociology for contemporary Latin America. Theory, Culture \& Society, Nottingham, v. 26, n. 1, p. 112-133, 2009.

DÓRIA, C. A. Cadências e decadências do Brasil: o futuro da nação à sombra de Darwin, Haeckel e Spender. 2007. Tese (Doutorado em Sociologia) - Instituto de Filosofia e Ciências Humanas, Universidade Estadual de Campinas, Campinas.

EISENSTADT, S. N. Multiple modernities. Daedalus, Cambridge, v. 129, n. 1, p. 1-29, 2000.

EISENSTADT, S. N. Modernity and modernization. Sociopedia.isa, International Sociological Association, Madrid, v. 25, n. 1, p. 1-15, 2010.

FREYRE, G. Atualidade de Euclydes da Cunha. In: Conferência lida na Biblioteca do Ministério das Relações Exteriores, Rio de Janeiro, 1940. Disponível em: <http://bvgf.fgf.org.br/portugues/obra/opusculos/atualidade_euclides.htm> Acesso em: 17 fev. 2012.

FREYRE, G. Sociologia: introdução ao estudo dos seus princípios. Rio de Janeiro: José Olympio, 1973.

FREYRE, G. Manifesto regionalista. Maceió: Ed. Ufal, 1976.

FREYRE, G. Sobrados e mucambos: história da sociedade patriarcal no Brasil. Rio de Janeiro: Record, 1996. 
FREYRE, G. Casa-grande \& senzala: introdução à história da sociedade patriarcal no Brasil. Rio de Janeiro: Record, 2000a.

FREYRE, G. Novo mundo nos trópicos. Rio de Janeiro: Topbooks, $2000 \mathrm{~b}$.

FREYRE, G. Nordeste: aspectos da influência da cana sobre a vida e a paisagem do Nordeste do Brasil. São Paulo: Global, 2004.

FREYRE, G. O luso e o trópico. São Paulo: É Realizações, 2010.

GIDDENS, A. As conseqüências da modernidade. São Paulo: Ed. Unesp, 1991.

LARRETA, E. e GIUCCI, G. Gilberto Freyre: uma biografia cultural: A formação de um intelectual brasileiro: 1900-1936. Rio de Janeiro: Civilização Brasileira, 2007.

LEHMANN, D. Gilberto Freyre: a reavaliação prossegue. Horizontes Antropológicos, Porto Alegre, n. 29, p. 369-385, 2008.

MAIA, J. M. Pensamento brasileiro e teoria social: notas para uma agenda de pesquisa. Revista Brasileira de Ciências Sociais, São Paulo, v. 24, n. 71, p. 155$168,2009$.

MIGNOLO, W. The Idea of Latin America. Oxford: Blackwell Publishing, 2005.

PALLARES-BURKE, M. L. Gilberto Freyre: um vitoriano dos trópicos. São Paulo: Editora da UNESP, 2005.

PARSONS, T. 1971. The System of Modern Societies. Englewood Cliffs: PrenticeHall, Inc, 1971.

NICOLAZZI, F. À sombra de um mestre. Gilberto Freyre leitor de Euclides da Cunha. História, Franca, v. 26, p. 254-277, 2010.

QUIJANO, A. Colonialidade do poder, eurocentrismo e América Latina. In LANDER, Edgardo (org). A colonialidade do saber: eurocentrismo e ciências sociais. Buenos Aires: CLACSO, p. 227-278, 2005.

RIBEIRO, A. M. Darcy Ribeiro e o pensamento crítico latino-americano: diálogos com a epistemologia pós-colonial. Sinais - Revista Eletrônica de Ciências Sociais, Vitória, n. 9, v. 1, p. 12-31, 2011.

ROMERO, S. Compêndio de história da literatura brasileira. Rio de Janeiro: Imago/Ed. UFS, 2001.

SAID, E. Orientalism. New York: Vintage Books, 1979

SANTOS, A. C. V. R. As naturezas de Freyre: natureza e ecologia em Nordeste (1937) de Gilberto Freyre. 2008. Dissertação (Mestrado em Sociologia) - Instituto de Filosofia e Ciências Humanas, Universidade Estadual de Campinas, Campinas. 
SCHWARCZ, L. M. O espetáculo das raças: cientistas, instituições e questão racial no Brasil 1870-1930. São Paulo: Companhia das Letras, 1993.

SOUZA, J. A modernização seletiva: uma reinterpretação do dilema brasileiro. Brasília. Editora da UnB, 2000.

TAVOLARO, S. B. F. Existe uma modernidade brasileira? Reflexões em torno de um dilema sociológico brasileiro. Revista Brasileira de Ciências Sociais, São Paulo, v. 20, n. 59, p. 5-22, 2005.

TAVOLARO, S. B. F. À sombra do mato virgem...: natureza e modernidade em uma abordagem sociológica brasileira. Ambiente \& sociedade, São Paulo, v. XI, n. 2, p. 273-287, 2008.

TAVOLARO, S. B. F. Freyre, DaMatta e o lugar da natureza na singularidade brasileira. Lua Nova, São Paulo, n. 83, p. 217-257, 2011.

THOMAZ, O. R. Prefácio. In: FREYRE, G. Interpretação do Brasil: aspectos da formação social brasileira como processo de amalgamento de raças e culturas. São Paulo: Companhia das Letras, 2001.

$\mathrm{TIBI}, \mathrm{B}$. Europeanizing Islam or the Islamization of Europe: political democracy vs. cultural difference. In: BYRNES, Timothy and KATZENSTEIN, Peter J. (eds). Religion in an Expanding Europe. New York: Cambridge University Press, p. 204224, 2006.

VELHO, G. Gilberto Freyre: trajetória e singularidade. Sociologia, problemas e práticas, Lisboa, n. 58, p.11-21, 2008.

VILLAS-BÔAS, G. Mudança provocada: passado e futuro no pensamento sociológico brasileiro. Rio de Janeiro: Editora FGV, 2006.

WITTROCK, B. Modernity: one, none, or many? European origins and modernity as a global condition. Daedalus, Cambridge, v. 129, n.1, p. 31-60, 2000.

Recebido em: 16/03/2012

Aceite final: 15/06/2012 